\title{
Ekonomik Kompleksite ve İnsani Gelişmişlik İlişkisi: E7 Ülkeleri İçin Bir Analiz
}

\author{
Mustafa Necati ÇOBAN \\ Tokat Gaziosmanpaşa Üniversitesi, İktisadi ve İdari Bilimler Fakültesi, İktisat Bölümü \\ necati.coban@gop.edu.tr \\ ORCID ID: https://orcid.org/0000-0003-2839-4403
}

\begin{tabular}{lrr}
\hline Araştırma Makalesi & DOI: 10.31592 aeusbed.659563 \\
\hline Geliş Tarihi: 15.12 .2019 & Revize Tarihi: 02.06 .2020 & Kabul Tarihi: 18.06 .2020
\end{tabular}

\section{Atıf Bilgisi}

Çoban, M. N. (2020). Ekonomik kompleksite ve insani gelişmişlik ilişkisi: E7 ülkeleri için bir analiz. Ahi Evran Üniversitesi Sosyal Bilimler Enstitüsü Dergisi, 6(2), 467-479.

\section{Öz}

Ülkeler için üretken bilginin girdi olarak üretime dahil edilmesi, çıktı verimliliği ve ürün çeşitliliğinin ülkelerin gelişmesinde önemli rol oynadığ 1 ifade edilmektedir. Ekonomik kompleksite, ülkelerin sofistike mal üretimi kapsamında yetkinliğini ifade eden önemli bir kavram olarak betimlenmektedir. Çalışmada E-7 ülkeleri olarak nitelendirilen Brezilya, Çin, Endonezya, Hindistan, Meksika, Türkiye ve Rusya'ya ait 19932017 dönemini kapsayan veriler kullanılarak panel eşbütünleşme analizi ve panel nedensellik analizi gerçekleştirilmiştir. Belirtilen ülkeler ve belirtilen veri aralığ çerçevesinde çalışmada ekonomik kompleksite ile insani gelişmişlik kavramları arasındaki ilişkinin araştırılması amaçlanmaktadır. $\mathrm{Bu}$ amaç doğrultusunda ekonomik kompleksite göstergesi olarak Atlas Media tarafından yayınlanan Ekonomik Kompleksite Endeksi, insani gelişmişlik göstergesi olarak ise UNDP (Birleşmiş Milletler Kalkınma Programı) tarafından yayınlanan İnsani Geliş̧̧̧̧̧lik Endeksi kullanılmıştır. İki değişken arasındaki uzun dönemli ilişkinin Westerlund Panel Eşbütünleşme testi ile incelendiği çalışmada ulaşılan sonuçlar analiz edildiğinde E-7 ülkelerinde ekonomik kompleksite ve insani gelişmişlik değişkenleri arasında eşbütünleşme ilişkisine rastlanamadığı gözlemlenmiştir. Daha sonra Dumitrescu-Hurlin panel nedensellik analizinin gerçekleştirildiği çalışmada insani gelişmişlik değişkeninden ekonomik kompleksite değişkenine doğru tek yönlü panel nedensellik ilişkisinin bulunduğu tespit edilmiştir.

Anahtar Kelimeler: Ekonomik kompleksite, insani gelişmişlik, panel eşbütünleşme analizi, panel nedensellik analizi.

\section{The Relationship Between Economic Complexityand Human Development: An Analysis for E7 Countries}

\begin{abstract}
It is stated that inclusion of productive information as an input, output efficiency and product diversity play an important role in the development of countries.Economic complexity is described as an important concept that expresses the competence of countries in the context of sophisticated goods production. In the study described as E-7 countries Brazil, China, Indonesia, India, Mexico, Turkey and Russia panels using data from the 1993-2017 period, the panel cointegration analysis and causality analysis was performed.The study aims to investigate the relationship between economic complexity and human development concepts within the framework of the mentioned countries and the data range.For this purpose, Economic Complexity Index published by Atlas Media was used as an indicator of economic complexity and Human Development Index published by UNDP was used as an indicator of human development. When the long-term relationship between the two variables was analyzed by Westerlund Panel Cointegration test, it was observed that the cointegration relationship between economic complexity and human development variables was not found in E-7 countries.Then, in the study which carried out the Dumitrescu-Hurlin panel causality analysis, it was found that there was a one-way panel causality relationship from human development variable to economic complexity variable.

Keywords: Economic complexity, human development, panel cointegration analysis, panel causality analysis.
\end{abstract}

\section{Giriş}

Refah yaklaşımları içerisinde kişi başına düşen Gayri Safi Yurt İçi Hasılanın (GSYİH) refahı açıklamada yetersiz kaldığını, refahın sadece iktisadi boyutunu ifade ettiğini öne süren görüşler oldukça fazladır. Kişi başına düşen GSYİH’nin refahın sosyal yönünü açıklamada yetersiz kaldığı yönündeki görüşler bu kapsamda yeni sosyal refah yaklaşımlarının gündeme gelmesini sağlamıştır. Bu yaklaşımlar içerisinde insani gelişme, özellikle son yıllarda refah ile alakalı olarak gerçekleştirilen 
çalışmalarda sıklıkla yer alan ve refahın sosyal yönünü de kapsayan bir kavram olarak nitelendirilmektedir.

Ekonomik kompleksite veya diğer bir deyişle ekonomik karmaşıklık, ülkelerin ürettikleri ürün çeşitliliğinden yola çıkılarak tanımlanan, ülkelerarası gelişmişlik seviyelerini açıklamada yardımcı olan ve ülkelerin üretim kapsamındaki yetkinliklerini ifade eden bir kavram olarak ifade edilmektedir. Ekonomik kompleksite, ülkelerin üretkenlik düzeylerini tanımlamakta olup çok daha fazla üretken bilginin girdi olarak üretime dâhil edildiği ülkelerde ürün çeşitliliğinin fazla olacağını ve ayrıca teknolojik kapsamda gelişmiş ve üretken bilginin yoğun olarak kullanıldığı ürünlerin üretileceğini ifade etmektedir (Hidalgo ve Hausmann, 2009).

Bir ülkenin üretiminin karmaşıklığı (üretmiş olduğu ürünlerin çeşitliliği ve sofistike olması), çeşitli ürünler üretilebilmesi için bir araya gelen üretken bilginin çeşitliliğini yansıtmaktadır (Inoua, 2016). Bir ekonominin ürün (hizmet dahil) üretme yeteneği, bir ülkede mevcut olan yeteneklerin sayısına ve yeteneklerin birbirini tamamlama yollarına bağlıdır (van Dam ve Frenken, 2019).

Ülkelerin ekonomik kompleksite düzeyleri, ülkelerin karşılaştırmalı üstünlükle ihraç ettikleri ürün sayısı ve bu ürünlerin yaygınlığı ve yine üründe karşılaştırmalı üstünlüğü ortaya çıkaran ülke sayısı ile belirlenmektedir (Hausmann, Hidalgo, Stock ve Yıldırım, 2014). Ülkelerin ekonomik karmaşıklık düzeylerinin ölçülmesi, gelecekte ülkelerin ekonomik büyüme düzeylerini büyük oranda öngördüğü için büyük ilgi görmüş̧ür. Ekonomik büyüme ve ortalama gelir seviyesi gibi makroekonomik göstergeler, mutlak yoksulluk ve sosyal refah düzeyleri gibi kavramlar ile korelasyon içerisinde olduğundan ötürü ekonomik karmaşıklık kavramının sosyal refahla da ilişkilendirilmesine neden olmaktadır (Bourguignon, 2004; Ravallion, 2004).

Ekonomik karmaşıklık üretilen malların karmaşıklı̆̆ını ve endüstriyel yapılardaki farklılıkları ele alarak bir ülkenin üretken yapısını betimlemektedir (Lapatinas, Garas, Boleti ve Kyriakou, 2019). Eğer bölgeler, teknolojik olarak gelişim göstermek için ve ekonomik kalkınma düzeylerini iyileştirmenin bir yolu olarak daha sofistike ürünler üretmeye karar verirlerse, ekonomik karmaşıklığın kaldıraçlarını belirlemek ve sanayi politikalarının buna göre uyumlulaştırılması önem arz edecektir (Antonietti ve Burlina, 2020).

Ekonomik kompleksite, ürünlerin karmaşıklığı ve çeşitliliği ile ülkelerin gizli kalmış endüstriyel potansiyellerini ortaya koymada büyük önem taşımaktadır. Ekonomik karmaşıklık veya ekonomik kompleksite terimi, her ulusal ekonominin sahip olduğu ve ekonomik olarak kazanç getirecek üretimin gerçekleştirilmesini sağlayan fakat parasal nitelikte olmayan, ticarete konu olmayan varlık veya kabiliyeti ifade eder. Parasal olmayan bu değerlerin ölçülmesi ekonomi için kilit bir unsurdur. Çünkü bu durum, ülkelerin gelecekte ekonomik büyümeleri için itici bir unsur olan bir ülkenin gizli potansiyeli hakkında yeni bilgiler ortaya çıkarabilir (Pietronero, Cristelli ve Tacchella, 2013).

Gelişmiş ve az gelişmiş ülkeler arasındaki üretim yapıları kapsamındaki farklar incelendiğinde gelişmiş ve zengin ülkelerde ürün farklılıklarının oldukça fazla olduğu ve genelde sofistike ürünler ürettikleri gözlemlenmektedir. Fakat az gelişmiş ve fakir ülkelerde ise ürün farklılıkları olmadığı ve ürettikleri ürünlerin daha çok ilkel ürünler olduğu görülmektedir (Hausmann, Hidalgo, Bustos, Coscia, Chung, Jimenez, Simoes ve Yildırım, 2011).

Japonya, Almanya, İsviçre ve İsveç gibi ülkelerin ekonomik karmaşıklık kapsamında genellikle ilk 10 ülke içerisinde yer aldığı bilinmektedir. İşçi başına daha yüksek katma değer elde edilen bu ülkelerde özellikle üretim tekniklerinin daha sofistike olduğu ve ekonomik kalkınmışlık göstergeleri kapsamında gelişmiş ülkeler içerisinde yer aldıkları görülmektedir (Gala, Rocha ve Magacho, 2018).

Ekonomik kompleksite yaklaşımına göre eğer bir ürün dünyada çok sayıda ülke tarafından ihraç ediliyorsa o ülkelerin ekonomik kompleksite seviyelerinin düşük olacağı ifade edilmektedir. 
Fakat ülkelerin ürettikleri ürünler çok sınırlı sayıdaki ülkeler tarafından ihraç ediliyorsa bu ülkelerin ekonomik kompleksite seviyeleri yüksektir (Mariani, Vidmer, Medo ve Zhang, 2015). Ülkelerin ancak üretken bilgiyi girdiye dönüştürerek, beceri ve yeteneklerini verimli oldukları alanlarda değerlendirerek daha hızlı ekonomik büyüme gerçekleştirmeleri beklenmektedir. Bu kapsamda geride olan ülkelerin yeteneklerini kullanamadıkları ve bundan dolayı ülkeler arası gelişmişlik yönünden farkl1lıklar oluştuğu ifade edilmektedir (Hidalgo ve Hausmann, 2009).

Ekonomik kompleksite ve iktisadi değişkenler arasındaki ilişkilerin araştırmacıların dikkatini çektiği gözlemlenmektedir. Ekonomik kompleksite ile gelir eşitsizliği ve kalkınma kavramları arasındaki ilişkisiyi analiz eden çalışmalarla beraber özellikle ekonomik kompleksite ve ekonomik büyüme arasındaki ilişkinin incelendiği çalışmalara daha çok rastlanmaktadır. Ekonomik kompleksite ile gelir eşitsizliğini inceleyen çalışmalar arasında Hartmann, Guevara, Jara-Figueroa, Aristaran ve Hidalgo (2017), ekonomik kompleksite, kurumlar ve gelir eşitsizliği kavramları arasındaki ilişkiyi incelemişlerdir. 1963-2008 dönemine ait verilerin kullanıldığ 1 ve 150'den fazla ülkenin araştırıldığ1 çalışmada çok değişkenli regresyon analizi gerçekleştirilmiştir. Ekonomik kompleksite ile gelir eşitsizliği arasında negatif yönlü ve istatistiksel olarak anlamlı bir ilişkinin varlığı tespit edilmiştir. Bu çalışmada elde edilen sonuçtan farklı olarak Lee ve $\mathrm{Vu}$ (2019), ekonomik kompleksitenin gelir eşitsizliği üzerine etkilerinin incelendiği, 1965-2014 yılları arası verilerin kullanıldığı ve 113 ülkenin araştırıldığı çalışmada ekonomik kompleksite düzeyindeki artışların gelir eşitsizliğini artırdığı bulgusuna ulaşmıştır. Gala, Rocha ve Magacho (2018) ise ekonomik kompleksitenin kalkınma üzerine etkilerini analiz etmiş ve ekonomik kompleksitenin ülkeler arasında yakınsama ve raksamayı açıklamada önemli olduğunu ortaya koymuştur.

Yine ekonomik kompleksite ile farklı değişkenler arasındaki ilişkinin incelendiği gözlemlenmektedir. Erkan ve Yıldırımcı'nın (2015) Türkiye için gerçekleştirdikleri çalışmada ekonomik kompleksite düzeyi istatistiksel olarak analiz edilmiştir. Bu analiz sonucunda Türkiye'nin emek yoğun üretimde uzmanlaştı̆̆ bulgusuna ulaşılmıştır. Yine Can ve Doğan (2018), ekonomik kompleksite ve finansal gelişme arasındaki ilişkiyi araştırmışlardır. Türkiye örnekleminde gerçekleştirilen çalışmada finansal gelişmenin ekonomik kompleksiteyi pozitif yönde etkilediği bulgusuna ulaşılmıştır. Neagu ve Teodoru (2019), Avrupa Birliği ülkelerinde ekonomik karmaşıklık, enerji tüketim yapısı ve sera gazı emisyonu arasındaki uzun dönem ilişkisini incelemişlerdir. Çalışmada ulaşılan sonuçlara bakıldığında ekonomik karmaşıklık, enerji tüketim yapısı ve sera gazı emisyonları arasında uzun dönem ilişkisi tespit edilmiştir. Khan, Khan ve Khan (2020), ekonomik kompleksite ve doğrudan yabancı yatırımlar arasındaki ilişkiyi araştırmışlardır. Çin'in incelendiği çalışmada ekonomik karmaşıklık ile doğrudan yabancı yatırımlar arasındaki uzun dönemde çift yönlü ve kısa dönemde tek yönlü nedensel ilişki doğrulanmıştır.

Ekonomik kompleksitenin karbon emisyonları üzerindeki etkilerini farklı gelişmişlik düzeylerindeki 55 ülke kapsamında araştıran Doğan, Saboori ve Can (2019), ekonomik kompleksitenin çevre üzerinde oldukça etkili olduğu bulgusuna ulaşmışlardır. Ekonomik kompleksite, düşük ve yüksek orta gelirli ülkelerde çevresel bozulmayı artırmış ve yüksek gelirli ülkelerde karbon emisyonlarını kontrol etmiştir. İthal ürün çeşitlendirmesinin karbon emisyonları üzerindeki etkisini inceleyen $\mathrm{Hu}$, Can, Paramati, Doğan ve Fang (2020), ithal ürün çeşitlendirmesinin gelişmiş ülkelerin karbon emisyonları üzerinde olumsuz, gelişmekte olan ülkelerin karbon emisyonları üzerinde ise pozitif etkiye sahip olduğunu ortaya koymuştur. Doğan, Madaleno, Tiwari ve Hammoudeh (2020), gelişmiş ve gelişmekte olan 63 ülkede ihracat kalitesi, ekonomik büyüme, kentleşme, ticari açıklık ve toplam enerji kullanımının karbon emisyonları üzerindeki etkisini araştırmıştır. Çalışmada ağırlıklı olarak alt ve üst orta gelirli ülkelerde, ihracat ürün kalitesindeki iyileşmelere öncelik verilmesi gerektiği sonucuna ulaşılmıştır. Can, Doğan ve Saboori (2020), gelişmekte olan 84 ülkede ihracat ürün çeşitlendirmesinin karbon emisyonları üzerine etkisini araştırmışlardır. Bulgulara göre gelişmekte olan 84 ülkede ürün çeşitlendirme, karbon emisyonları üzerinde olumlu ve anlamlı bir etkiye sahiptir.

Ülkelerin mal ve hizmet üretiminde yarattıkları katma değerin ve mal ve hizmet çeşitliliğinin GSYİH'daki artışlara etkisinin olup olmadığ merak konusu olmuştur. Konu ile ilgili olarak Chavez, Mosqueda ve Gomez-Zaldivar (2017), ekonomik kompleksite ve bölgesel ekonomik büyüme 
arasındaki ilişkiyi analiz etmişlerdir. Meksika eyaletlerinin 1998-2013 dönemine ait verilerinin kullanılarak araştırıldığ1 çalışmada kuzeyde yer alan eyaletlerin ekonomik kompleksitelerinin daha yüksek, orta kesimde yer alan eyaletlerin ekonomik kompleksitelerinin orta seviyede olduğu ve güneydekilerin ise ekonomik kompleksite seviyelerinin en düşük seviyede olduğu gözlemlenmiştir. İncelenen eyaletlerde ekonomik kompleksite ile ekonomik büyüme arasındaki ilişkinin yönünün pozitif olduğu tespit edilmiştir.

Benzer şekilde Çeştepe ve Çağlar (2017), Stojkovski ve Kocarev (2017), Zhu ve Li (2017), Soyyiğit (2018), Britto, Romeiro, Freitas ve Coelho (2019) ve Yıldız ve Akbulut Yildız (2019) ekonomik kompleksite ile ekonomik büyüme arasındaki ilişkiyi analiz etmişlerdir. Çalışmaların ekseriyetinde genel olarak ekonomik kompleksitenin ekonomik büyümeyi olumlu yönde etkilediği bulgusuna ulaşılmıştır. Bu çalışmalar içerisinde diğer çalışmalardan farklı olarak Soyyiğit'in (2018), OECD (Ekonomik Kalkınma ve İşbirliği Örgütü [Organisation for Economic Cooperation and Development) kurucu ülkelerini incelediği çalışmada, yapılan panel eşbütünleşme analizi sonucunda iki değişken arasında anlamlı bir ilişki ortaya konulamamıştır. Ve yine Stojkovski ve Kocarev'in (2017) Güneydoğu ve Orta Avrupa ülkelerini inceledikleri çalışmada gerçekleştirilen panel veri analizi sonucunda ekonomik kompleksitenin uzun vadede büyümeyi olumlu yönde etkilediği tespit edilmiştir. Fakat kısa vadede üretken bilginin Güneydoğu ve Orta Avrupa ülkelerinde gelir değişikliklerine etkisinin bulunmadığı sonucuna ulaşılmıştır.

Ekonomik kompleksitenin sadece bir ekonomik refah göstergesi olarak kişi başına düşen GSYIH üzerindeki etkilerinin analiz edilmesi, ekonomik kompleksite ile refah değişkenleri arasındaki ilişkiyi tam olarak açıklamayabilir. Bunun için ekonomik kompleksite ile bir sosyal refah göstergesi olarak insani gelişmişlik arasındaki ilişkinin de analiz edilmesi gerekebilir. Konu ile ilgili literatür incelendiğinde Lapatinas'ın (2016) 126 ülkeye ait 1965-2005 dönemine ait verilerini kullanarak ekonomik kompleksite ile insani gelişmişlik arasındaki ilişkiyi analiz ettiği görülmektedir. Dinamik panel veri analizinin gerçekleştirildiği çalışmada ekonomik kompleksitenin insani gelişme üzerine nedensel bir etkisi olduğuna dair bir kanıt bulunamamıştır.

Ekonomik kompleksite ile insani gelişmiş̧lik arasındaki ilişkiyi analiz eden diğer çalışmalara bakıldığında farklı sonuçlara ulaşıldığı görülmektedir. Ferraz, Moralles, Campoli, Oliveira ve Rebelatto (2018), ekonomik kompleksite ve insani gelişmişlik ilişkisini araştırdıkları çalışmada 20102014 yılları arası döneme ait verileri kullanarak veri zarflama analizi gerçekleştirmişlerdir. Asya ve Latin Amerika ülkelerini incelemişlerdir. Bu çalışmada incelenen ülkelerde ekonomik kompleksite seviyesi yüksek olan ülkelerin insani gelişmişlik düzeyinin daha yüksek olduğu bulgusu elde edilmiştir. Bu çalışmanın dışında Ferraz, Moralles, Costa ve Rebelatto (2019), ekonomik kompleksite ve insani gelişmişlik arasındaki ilişkiyi hem geleneksel veri zarflama analizi yöntemi ile hem de gevşek tabanlı etkinlik ölçümü ile analiz ederek bu yöntemlerle elde edilen bulguları karşılaştırmışlardır. 50 ülkenin incelendiği çalışmada geleneksel veri zarflama yönteminin aksine gevşek tabanlı etkinlik ölçümü ile ekonomik kompleksite ve insani gelişme ilişkisinin daha iyi yansitıldığ ve geleneksel veri analizi ile elde edilen sonuçlarda etkin ülkelere dair bulguların abartılı olduğu bulgusuna ulaşılmıştır. Bir diğer çalışmada ise Soyyiğit, Eren ve Akis (2019), 1992-2017 dönemine ait verileri kullanarak G-20 ülkeleri üzerinde insani gelişmişlik ve ekonomik kompleksite arasındaki ilişkiyi incelemiştir. Çalışma kapsamında elde edilen bulgular gözlemlendiğinde ABD (Amerika Birleşik Devletleri) dışındaki ülkelerin tamamında insani gelişmişliğin ekonomik kompleksite üzerinde etkili olduğu tespit edilmiştir. İnsani gelişmişliğin ekonomik kompleksite üzerindeki etkisi Almanya, Fransa, İngiltere, Japonya ve İtalya'da negatif, diğer ülkelerde ise pozitif yönlü olmuştur. Avustralya ve Kanada dişındaki tüm gelişmiş G-20 ülkelerinde insani gelişmişliğin ekonomik kompleksite üzerindeki etkisinin yönünün negatif olduğu bulgusuna ulaşılmıştır.

$\mathrm{Bu}$ çalışmada ise E-7 ülkelerinde ekonomik kompleksite ve insani gelişmişlik ilişkisinin araştırılması amaçlanmaktadır. E-7 ülkelerinin gelecekte en hızlı büyüyecek gelişmekte olan ülkeler olarak nitelendirilmeleri, çalışmada E-7 ülkelerinin seçiminde etkili olmuştur. Bunun dışında ilgili literatürde bu zamana kadar gerçekleştirilen çalışmalarda daha çok ekonomik kompleksite ve ekonomik büyüme ilişkisinin incelendiği, refahın sosyal yönünün ihmal edildiği gözlemlenmektedir. 
Çalışma özellikle bir sosyal refah göstergesi olarak İnsani Gelişmişlik Endeksi'nin kullanılması yönünden önem arz etmektedir. Çalışma kapsamında 1993-2017 dönemine ait veriler kullanılarak panel eşbütünleşme analizi ve panel nedensellik analizi gerçekleştirilmiştir. Çalışmada ilk olarak yöntem bölümü yer almaktadır. Sonrasında ampirik bulgulara yer verilmiştir. Nihai olarak ise sonuç bölümüyle çalışmada elde edilen bulgulara yönelik değerlendirme yapılmıştır.

\section{Yöntem}

Çalışmada E-7 ülkeleri olarak nitelendirilen Brezilya, Çin, Endonezya, Hindistan, Meksika, Türkiye ve Rusya'ya ait 1993-2017 dönemine ait veriler kullanılarak panel eşbütünleşme analizi gerçekleştirilmiştir. İncelenecek olan veri aralığının tespit edilmesinde ilgili dönemde tüm değişkenler için verilerin mevcut olması etkili olmuştur.

\section{Verilerin Elde Edilmesi}

Ekonomik Kompleksite Endeksi ve İnsani Gelişmişlik Endeksi arasındaki ilişkinin incelendiği çalışmada Ekonomik Kompleksite Endeksi'ne dair veriler Atlas Medya'dan, İnsani Gelişmişlik Endeksi'ne dair veriler ise UNDP veritabanından elde edilmiştir. Çalışmada yer alan değişkenlere ait bilgiler Tablo 1'de yer almaktadır.

Tablo 1

Çalışmada Kullanılan Değişkenler

\begin{tabular}{lll}
\hline Değişken & Açıklama & Kaynak \\
\hline HDI & İnsani Gelişme Endeksi & UNDP \\
ECI & Ekonomik Kompleksite Endeksi & Atlas Media \\
\hline
\end{tabular}

Çalışmada ilk olarak E-7 Ülkeleri için yatay kesit bağımlılığı sınaması gerçekleştirilecektir. Daha sonra ise birim kök testi ve homojenlik testleri gerçekleştirilmiştir. Tüm bu aşamalardan sonra ise eşbütünleşme ilişkisinin var olup olmadığı test edilecektir.

\section{Verilerin Analizi}

Veriler ilgili veri tabanlarından temin edildikten sonra çalışmada sırasıyla birimler arası korelasyon, birim kök testi, homojenlik testi, panel eşbütünleşme testi ve panel nedensellik testi gerçekleştirilecektir. Çalışmada analizlerin yapılmasında Stata 14 paket programından faydalanılmıştır.

\section{Bulgular}

Hata terimlerinin birimlere göre bağımsız olması, panel veri modelleri içerisinde genel varsayımlardan birisidir. Fakat yatay kesit birimler boyunca hatalar eş zamanlı korelasyona sahip olabilmektedir. Bu da korelasyon matrisinin birim matris olmasının önüne geçmektedir. Bundan dolayı birimler arası korelasyonsuzluk varsayımının test edilmesi önem arz etmektedir (Tatoğlu, 2016).

Çalışmada birimler arası korelasyon Breusch-Pagan LM testi ile sınanmıştır. Panel veri modellerinde $\mathrm{N}<\mathrm{T}$ olan durumlarda Breusch-Pagan LM testi ile birimler aras1 korelasyon sınanabilmektedir. Modelin zaman boyutu 25, yatay kesit boyutu 7 olduğu için Breusch-Pagan LM testi uygulanabilmektedir.

Tablo 2

Breusch-Pagan LM Testi

\begin{tabular}{lll}
\hline & İstatistik Değeri & Olas1lık Değeri \\
\hline Breusch-Pagan LM Testi & 266.4 & 0.0000 \\
\hline
\end{tabular}


Tablo 2'de Breusch-Pagan LM testine dair bulgular yer almaktadır. Buna göre $H_{0}$ hipotezi reddedilmiş, birimler arası korelasyon olduğu tespit edilmiştir. Yatay kesitler arasında bağımlılık olduğunu ifade eden $H_{1}$ hipotezi kabul edilmiştir.

Yine çalışmada kullanılan HDI ve ECI değişkenleri için birimler arası korelasyonun varlı̆g 1 sınanmıştır. Bunun için Pesaran'ın CD testi kullanılmıştır. Pesaran (2004), yatay kesit bağımsızlığını sınama amacıyla önermiş olduğu testte ADF regresyonun tahmininden elde edilen kalıntıları kullanmaktadır. Her bir birimin kendisi dışında kalan tüm birimlerle korelasyonu Pesaran'ın CD testi aracılığıyla hesaplanmaktadır (Tatoğlu, 2017).

Tablo 3

Pesaran CD Testi

\begin{tabular}{lll}
\hline & CD Test İstatistiği & Olasılık Değeri \\
\hline ECI & 4.16 & 0.0000 \\
\hline HDI & 22.59 & 0.0000 \\
\hline
\end{tabular}

Tablo 3'te Pesaran CD testine dair sonuçlar bulunmaktadır. $H_{0}$ hipotezi reddedilmiş ve her iki değişken için birimler arası korelasyon tespit edildiği sonucuna ulaşılmıştır. Birimler arası korelasyonun varlığında ikinci kuşak panel birim kök testleri tercih edilmelidir.

Serilerin durağan olup olmaması, ekonometrik analizlerde önemli hususlardan birisidir. Serilerin durağanlığını sınama adına birim kök testleri geliştirilmiştir. Bu birim kök testleri sonucu seriler durağan olmazsa ve ancak farkında durağan hale geliyorlarsa panel eşbütünleşme analizleri gerçekleştirilmektedir.

Çalışma kapsamında serilerin durağanlığını sınama adına Im, Pesaran ve Shin (IPS) birim kök testi gerçekleştirilmiştir. Birimler arası korelasyonu dikkate alacak şekilde düzeltilen Im, Pesaran ve Shin birim kök testi, birimler arası korelasyon problemi ile karşılaşıldığı durumlarda kullanılabilen ikinci kuşak panel birim kök testleri içerisinde yer almaktadır (Tatoğlu, 2017).

Tablo 4

Im, Pesaran ve Shin (IPS) Birim Kök Testi

\begin{tabular}{llll}
\hline Değişkenler & İstatistik Değerleri & Olasılık Değerleri & Durağanlık \\
\hline HDI & -8.8680 & $0.0000^{*}$ & 1. Fark \\
ECI & -10.0663 & $0.0000^{*}$ & 1. Fark \\
\hline
\end{tabular}

*Bulgular 0.05 anlam düzeyinde anlamlıdır.

Im, Pesaran ve Shin panel birim kök testine dair bulgular Tablo 4 aracıllı̆ıyla görülmektedir. HDI ve ECI değişkenine ait serilerin birim kök içerdiği tespit edilmiş ve bu serilerin ancak birinci farkında durağan hale geldikleri gözlemlenmektedir. Birim kök içeren seriler arasında uzun dönemli ilişkinin varlığı eşbütünleşme testleri ile araştırılmaktadır. Fakat öncesinde homojenlik testi gerçekleştirilmelidir.

Sabit ve eğim parametreleri birimlere göre homojen veya heterojen olabilmektedir. Homojen veya heterojen olma durumu aynı zamanda uygulanacak olan eşbütünleşme testleri ve tahmin yöntemleri kapsamında farklılıkların ortaya çıkmasını sağlamaktadır. Bunun için uygulanacak yöntem gerçekleştirilmeden önce homojenlik testi gerçekleştirilmelidir (Tatoğlu, 2017).

Tablo 5

Swamy S Homojenlik Testi

\begin{tabular}{lll}
\hline & Ki-kare Test İstatistik Değeri & Olasılık Değeri \\
\hline Swamy S Testi & 310.28 & $0.0000 *$ \\
\hline *Bulgular 0.05 anlam düzeyinde anlamlıdır. & \\
\hline
\end{tabular}


Tablo 5'te Swamy S testine dair bulgular yer almaktadır. Ki-kare test istatistiği değeri ve olasılık değeri gözlemlenmektedir. Buna göre $H_{0}$ hipotezi reddedilmiş ve parametrelerin homojen olmadığ tespit edilmiştir. Parametreler birimden birime değişmekte, diğer bir deyişle heterojendir. $\mathrm{Bu}$ sonuçlardan yola çıkarak eşbütünleşme testleri içerisinde heterojen olanların sonuçlarına itimat edilmeli ve heterojen paneller için uygun olan tahmin yöntemleri kullanılmalıdır.

Gerçekleştirilen yatay kesit bağımlılığı, birim kök ve homojenlik testlerinden sonra sıradaki aşama değişkenler arası uzun dönem ilişkisinin test edilmesidir. Seriler düzeyde durağan olmadığından ötürü uzun dönemli ilişkinin varlığının test edilmesi panel eşbütünleşme testleri ile olmaktadır. Uzun dönem parametresinin homojen veya heterojen olmasına göre uygulanacak olan panel eşbütünleşme testi farklılaşmaktadır.

Tablo 6

Westerlund Panel Eşbütünleşme Testi

\begin{tabular}{llllll}
\hline İstatistik & İstatistik Değeri & Z İstatistiği & Olasılık Değeri & $\begin{array}{l}\text { Dirençli Kritik } \\
\text { Değerler }\end{array}$ \\
\hline $\mathrm{Gt}$ & & & 0.928 & 0.840 & \\
$\mathrm{Ga}$ & -1.302 & 1.462 & 0.986 & 0.960 & \\
$\mathrm{Pt}$ & -2.721 & 2.187 & 0.960 & 0.720 & \\
$\mathrm{~Pa}$ & -2.134 & 1.744 & 0.967 & 0.840 & \\
\hline
\end{tabular}

Çalışma kapsamında değişkenler arası uzun dönem ilişkisinin tespiti için Westerlund Panel Eşbütünleşme Testi uygulanmıştır. Bu test uzun ve kısa dönem parametrelerinde heterojenliğe izin vermektedir. Bu teste dair bulgular Tablo 6'da görülmektedir. Bulgular içerisinde $G_{t}, G_{a}, P_{t}$ ve $P_{a}$ test istatistikleri, $\mathrm{Z}$ istatistikleri, olasılık değerleri ve birimler arası korelasyonun varlığında geçerli bootstrap kritik değerleri ifade edilmektedir. Ulaşılan bu sonuçlara göre ekonomik kompleksite ve insani gelişmişlik değişkenleri arasında eşbütünleşme ilişkisine rastlanamamış ve $H_{0}$ hipotezi kabul edilmiştir.

Değişkenler arası uzun dönemli ilişkinin test edilmesinden sonraki aşama, değişkenler arası nedensellik ilişkisinin araştırılmasıdır. Değişkenlerin birinden diğerine doğru tek yönlü veya değişkenler arasında karşılıklı nedensellik ilişsisine rastlanabilmektedir. Nedensellik ilişkisinin araştırılması amacı 1le panel nedensellik testleri geliştirilmiştir.

Panelin heterojen ve homojen olma durumuna göre uygulanacak olan panel nedensellik analiz yöntemi farklılaşabilmektedir. Dumitrescu- Hurlin Panel Nedensellik Testi panelin heterojen olduğu durumlarda uygulanabilmektedir. Çalışmada incelenen model, heterojen bir panel olduğu için Dumitrescu-Hurlin Panel Nedensellik Testi gerçekleştirilebilmektedir.

Tablo 7

Dumitrescu-Hurlin Panel Nedensellik Testi

\begin{tabular}{lllll}
\hline$H_{0}$ Hipotezi & $\begin{array}{l}\text { W-bar } \\
\text { İstatistiği }\end{array}$ & $\begin{array}{l}\text { Z-bar } \\
\text { İstatistiği }\end{array}$ & Olasılık Değeri & Sonuç \\
ECI, HDI’nin nedeni değildir & 1.2198 & 0.4112 & 0.6809 & ECI $\nRightarrow$ HDI \\
& & & & \\
HDI, ECI'nin nedeni değildir & 14.0197 & 6.1251 & $0.0000^{*}$ & HDI $\Rightarrow$ ECI
\end{tabular}

*Bulgular 0.05 anlam düzeyinde anlamlıdır.

Tablo 7'de Dumitrescu-Hurlin Panel Nedensellik testine dair bulgular yer almaktadır. W-bar istatistiği değerleri, Z-bar istatistiği değerleri ve olasılık değerleri görülmektedir. ECI değişkeninden HDI’ya doğru bir nedensellik ilişkisine rastlanamamıştır. $H_{0}$ hipotezi kabul edilmiştir. HDI'dan 
ECI'ya doğru nedensellik ilişkisi incelendiğinde ise HDI'dan ECI'ya doğru tek yönlü bir panel nedensellik ilişkisinin var olduğu gözlemlenmektedir. $H_{0}$ hipotezi reddedilmiştir.

\section{Tartışma, Sonuç ve Öneriler}

Ekonomik kompleksite, ülkelerin üretim yapıları hakkında bilgi veren ve ülkelerin gelişmişliği kapsamında ölçüt olarak ele alınan bir kavram olarak belirtilmektedir. Bir ürün, sayıca çok ülke tarafından üretiliyorsa bu ürün sofistike bir mamül olarak nitelendirilmemektedir. Fakat bir ülkenin ürettiği ürün çok az ülke tarafından üretiliyorsa bu ürünü üreten ülkelerin gelişmiş üretim teknolojisine sahip olduğu, nitelikli ve katma değeri yüksek ürünler ürettikleri ve ekonomik kompleksite seviyelerinin yüksek olduğu ifade edilmektedir.

Ülkelerin ürettikleri ürüne üretken bilgi ve inovasyon katmaları o ürünün sofistike bir ürün olmasına olanak tanımaktadır. Çıktının verimli olması ve belirli bir beceri ve yetenek gerektirmesi bu ürünün diğer ülkeler tarafından kolaylıkla üretilemeyeceğini ifade etmektedir. Teknolojik olarak ileri seviyede olan ve ürün çeşitliliğini sağlamış ülkeler gelişmiş ülke kategorisi içerisinde sinıflandırılabilmektedir.

Çalışmada 1993-2017 dönemine ait veriler kullanılarak E-7 ülkeleri olarak nitelendirilen Brezilya, Çin, Endonezya, Hindistan, Meksika, Türkiye ve Rusya'da ekonomik kompleksite ve insani gelişme arasındaki ilişki araştırılmıştır. Panel eşbütünleşme analizinin yapıldığı çalışmada ilk olarak yatay kesit bağımlılığı test edilmiş, daha sonra sirasıly birim kök testi ve homojenlik testi gerçekleştirilmiştir. Westerlund eşbütünleşme testi ile değişkenler arası uzun dönemli ilişkinin varlığı araştırılmış, akabinde Dumitrescu-Hurlin panel nedensellik analizi yapılmıştır.

Elde edilen bulgular incelendiğinde değişkenler arası eşbütünleşme ilişkisine rastlanamadığ 1 gözlemlenmiştir. Sonrasında değişkenler arası nedensellik ilişkisinin araştırıldığı Dumitrescu-Hurlin panel nedensellik testi sonuçlarına göre ise insani gelişmeden ekonomik kompleksiteye doğru tek yönlü panel nedensellik ilişkisinin olduğu tespit edilmiştir.

Ulaşılan bulguların bir kısmının literatürdeki birtakım çalışmalarda elde edilen bulgularla uyum içerisinde olduğu gözlemlenmektedir. Lapatinas (2016), ekonomik kompleksitenin insani gelişmişlik üzerinde nedensel bir etkisinin olmadığını tespit etmiştir. Bu çalışmada elde edilen bulgular da bu yöndedir. E-7 ülkelerinde ekonomik kompleksitenin insani gelişmişlik üzerinde nedensel bir etkisinin olmadığı, bilakis insani gelişmişliğin ekonomik kompleksite üzerinde nedensel bir etkisinin bulunduğu tespit edilmiştir. Konu ile ilgili literatürde çok fazla çalışma bulunmadığı için çok kapsamlı bir karşılaştırma olanağı bulunmamaktadır.

Çalışma kapsamında ulaşılan sonuçlardan yola çıkarak ülkelerin üretimde uzmanlaşması, ürün çeşitlendirmesi ve sofistike mamüller üretebilmeleri için öncelikle refahı tesis etmeleri gerektiği ifade edilebilir. Sosyal refah tesis edilmeli, bireylerin yaşam konforlarının artırılmasına yönelik faaliyetler gerçekleştirilmelidir. İnsani gelişmişlik için önemli olan eğitim ve sağlık gibi beşerî sermaye unsurlarına yatırım yapılmalıdır. Ulaşılan bulgular, E-7 ülkeleri için insani gelişmişlik seviyesinin arttırılmasına yönelik politikaların uygulanmasının bu ülkelerdeki ekonomik kompleksite düzeyini pozitif yönde etkileyeceğini göstermektedir. Konu ile ilgili olarak araştırmacıların farklı ülke grupları ve farklı uluslararası ekonomik oluşumlar çerçevesinde yapacağ 1 çalışmaların literatüre önemli katkı sağlayacağı düşünülmektedir.

\section{Kaynaklar}

Antonietti, R. and Burlina, C. (2020). From variety to economic complexity: Empirical evidence from Italian regions, Papers in Evolutionary Economic Geography, http://econ.geo.uu.nl/peeg/peeg1930.pdf adresinden 07.05.2020 tarihinde erişim sağlanmıştır. 
Bourguignon, F. (2004). The poverty-growth-inequality triangle, Indian Council for Research on International Economic Relations, New Delhi Working Paper, No. 125. New Delhi: Indian Council for Research on International Economic Relations, https://ideas.repec. org/p/ind/icrier/125.html adresinden 07.05.2020 tarihinde erişim sağlanmıştır.

Britto, G., Romero, J. P., Freitas, E. and Coelho, C. (2019). The great divide: Economic complexity and development paths in Brazil and the republic of Korea. CEPAL Review, (127), 191-213.

Can, M. ve Doğan, B. (2018). Ekonomik kompleksite ve finansal gelişme ilişkisi: Türkiye örnekleminde ampirik bir analiz. Finans Politik \& Ekonomik Yorumlar, 55(638), 5-16.

Can, M., Dogan, B. and Saboori, B. (2020). Does trade matter for environmental degradation in developing countries? New evidence in the context of export product diversification. Environmental Science and Pollution Research, (27), 14702-14710.

Chavez, J. C., Mosqueda, M.T. and Gomez-Zaldivar, M. (2017). Economic complexity and regional growth performance: Evidence from the Mexican economy. The Review of Regional Studies, 47(2), 201-219.

Çeştepe, H. ve Çağlar, O. (2017). Ürün sofistikasyonu ve ekonomik büyüme ilişkisi: Panel veri analizi. Uluslararası Yönetim İktisat ve İşletme Dergisi, (ICMEB17 Özel Sayıs1), 992-1000.

Doğan, B., Saboori, B. and Can, M. (2019). Does economic complexity matter for environmental degradation? An empirical analysis for different stages of development. Environmental Science and Pollution Research, (26), 31900-31912.

Dogan, B., Madaleno, M., Tiwari, A.K. and Hammoudeh, S. (2020). Impacts of export quality on environmental degradation: Does income matter?. Environmental Science and Pollution Research, (27), 13735-13772.

Erkan, B. and E. Yildirımc1, (2015). Economic complexity and export competitiveness: The case of Turkey. Procedia-Socialand Behavioral Sciences, (195), 524-533.

Ferraz, D., Moralles, H. F., Campoli, J. S., Oliveira, F. C. R. and Rebelatto, D. A. N. (2018). Economic complexity and human development: DEA performance measurement in Asia and Latin America. Gestão \& Produção, 25(4), 839-853.

Ferraz, D., Moralles, H. F., Costa, N. and Rebelatto, D. A. N. (2019). Economic complexity and human development: Comparing traditional and slack based data envelopment analysis models. https://ssrn.com/abstract=3402211 adresinden $\quad 03.03 .2020 \quad$ tarihinde erişim sağlanmıştır.

Gala, P., Rocha, I. and Magacho, G. (2018). The structuralist revenge: Economic complexity as an important dimension to evaluate growth and development. Brazilian Journal of Political Economy, 38(2), 219-236.

Hartmann, D., Guevara, M.R., Jara-Figueroa, C., Aristaran, M. and Hidalgo, C.A. (2017). Linking economic complexity, institutions and income inequality. World Development, (93), 75-93.

Hausmann, R., Hidalgo, C. A., Bustos, S., Coscia, M., Chung, S., Jimenez, J., Simoes, A. and Yildirım, M. A. (2011). The atlas of economic complexity: Mapping paths to prosperity. Center for International Development at Harvard Universityand Macro Connections MIT Media Lab. 
Hausmann, R., Hidalgo, C. A., Stock, D. P., and Yildirim, M. A. (2014). Implied comparative advantage (Working Paper). Cambridge, MA: Center for International Development at Harvard University.

Hidalgo, C. A. and Hausmann, R. (2009). The building blocks of economic complexity. PNAS, 106 (26), 10570-10575.

Hu, G., Can, M., Paramati, S. R., Doğan, B. and Fang, J. (2020). The effect of import product diversification on carbon emissions: New evidence for sustainable economic policies. Economic Analysis and Policy, (65), 198-210.

Inoua, S. (2016). A simple measure of economic complexity, http://arxiv.org/abs/1601.05012 adresinden 07.05.2020 tarihinde erişim sağlanmıştır.

Khan, H., Khan, U. and Khan, M. A. (2020). Causal nexus between economic complexity and FDI: Empirical evidence from time series analysis. Chin. Econ. 2020, 1-21.

Lapatinas, A. (2016). Economic complexity and human development: Anote. Economics Bulletin, $36(3), 1441-1452$.

Lapatinas, A., Garas, A., Boleti, E. and Kyriakou, A. (2019). Economic complexity and environmental performance: Evidence from a world sample. Munich Personal RePEc Archive, https://mpra.ub.uni-muenchen.de/92833/1/MPRA_paper_92833.pdf adresinden 07.05.2020 tarihinde erişim sağlanmıştır.

Lee, K. K. and Vu, T. V. (2019). Economic complexity, human capital and income inequality: Acrosscountry analysis. Japanese Economic Review, 1-31.

Mariani, M. S., Vidmer, A., Medo, M. and Zhang, Y. C. (2015). Measuring economic complexity of countries and products: Which metric to use? Eur. Phys. J. B., (88), 293.

Neagu O. and Teodoru, M. C. (2019). The relationship between economic complexity, energy consumption structure and green house gas emission: Heteregeneous panel evidence from the EU countries. Sustain, 2(497), 1-29.

Pietronero, L., Cristelli, M. and Tacchella, A. (2013). New metrics for economic complexity: Measuring the intangible growth potential of countries. Conference at Institute for New Economic Thinking, Hong Kong.

Ravallion, M. (2004). Pro-poorgrowth: A primer, Policy Research Working Paper, No. ID 610283, World Bank, http:// dx.doi.org/10.1596/1813-9450-3242. adresinden 07.05.2020 tarihinde erişim sağlanmıştır.

Soyyiğit, S. (2018). OECD kurucu ülkelerinde ekonomik kompleksite düzeyi ile kişi başına düşen GSYIH arasındaki ilişki: Panel eşbütünleşme analizi. Selçuk Üniversitesi Sosyal Bilimler Meslek Yüksekokulu Dergisi, 21(2), 374-392.

Soyyiğit, S., Eren, E. and Akis, E. (2019). Investigation of the relationship between economic complexity level and human development level: Comparison of developed and developing countries. Journal of Management Marketing and Logistics, 6(3), 162-174.

Stojkovski, V. and Kocarev, L. (2017). The relationship between growth and economic complexity: Evidence from Southeastern and Central Europe. MPRA Paper No: 7783, Munich Personel RePEc Archive. 
Tatoğlu, F. Y. (2016). Panel veri ekonometrisi. İstanbul: Beta Yayınları.

Tatoğlu, F. Y. (2017). Panel zaman serileri analizi. İstanbul: Beta Yayınları.

van Dam, A. and Frenken, K. (2019). Variety, complexity and economic development. Papers in Evolutionary Economic Geography (PEEG).

Yıldız, B. ve Akbulut Yıldız, G. (2019). Ekonomik karmaşıklık ile ekonomik büyüme arasındaki ilişki: Panel Bootstrap Granger nedensellik analizi. Uluslararası Yönetim İktisat ve İsletme Dergisi, 15(2), 329-340.

Zhu, S. and Li, R. (2017). Economic complexity, human capital and economic growth: Empirical research based on cross-country panel data, Applied Economics, 49(38), 1-14. 


\section{Extended Abstract}

\section{Introduction}

Among the welfare approaches, there are many arguments suggesting that GDP per capita is insufficient in explaining prosperity and that it expresses only the economic dimension of prosperity. The perceptions that GDP per capita was insufficient to explain the social aspect of welfare brought new social welfare approaches to the agenda. Among these approaches, human development has been described as a concept which is frequently included in the studies carried out especially in relation to welfare in recent years and that includes the social aspect of welfare.

Economic complexity is defined as a concept which is defined by the product diversity produced by countries, helps to explain the levels of development between countries and expresses the competencies of countries in production. Economic complexity defines the level of productivity of the countries and states that product diversity will be high in the countries where more productive information is included in the production as well as the products which use advanced and productive information intensively in the technological context.

\section{Method}

In the study described as E-7 countries Brazil, China, Indonesia, India, Mexico, Turkey and Russia panels using data from the 1993-2017 period, the panel cointegration analysis and causality analysis was performed. The existence of data for all variables in the relevant period was effective in determining the range of data to be examined. In this study, the relationship between the Economic Complexity Index and the Human Development Index was analyzed and the data related to the Economic Complexity Index were obtained from Atlas Media and the Human Development Index was obtained from the UNDP database. Stata 14 package program was used in the analysis.

\section{Findings}

Horizontal cross-section dependency test will be performed for E-7 Countries. Then, unitroot test and homogeneity tests will be performed. After all these stages, the existence of cointegration relationship will be tested. The correlation between units was tested with Breusch-Pagan LM test. Accordingly there was a correlation between units. In the scope of the study, Im, Pesaran and Shin (IPS) unit root tests were performed to test the stability of the series. The series of HDI and ECI variables were found to contain unit roots and it was observed that these series became the first aware stationary. The existence of long-term relationship between unit root-containing series is investigated by cointegration tests. However, the homogeneity test must be performed beforehand. For this purpose, Swamy S test was performed and it was found that the parameters were not homogeneous. The parameters are heterogeneous. Since the series is not stationary at the level, the existence of the long-term relationship is tested by panel cointegration tests.

In the scope of the study, Westerlund Panel Cointegration Test was applied to determine the long term relationship between variables. This test allows heterogeneity in long and short term parameters. According to the Westerlund Panel Cointegration test results, no cointegration relationship was found between the variables of economic complexity and human development. After testing the long-term relationship between variables, the next step is to investigate the causal relationship between the variables. The Dumitrescu-Hurlin Panel Causality Test can be applied in cases where the panel is heterogeneous. Since the model examined in thestudy is a heterogeneous panel, the Dumitrescu-Hurlin Panel Causality Test can be performed. According to the results of Dumitrescu-Hurlin panel causality test, no causality relationship from ECI variableto HDI was found. However, it is observed that there is a unidirectional panel causality relationship from HDI to ECI. 


\section{Results}

Economic complexity is defined as a concept that provides information about the productio structures of countries and is taken as a criterion in the context of the development of countries. If a product is produced by a large number of countries, it is not considered a sophisticated product. However, if a product produced by a country is produced by very few countries, it is stated that the countries producing this product have advanced production technology, produce qualified and high value-added products and their economic complexity levels are high.

Countries' productive knowledge and innovation to the product they produce allows it to be a sophisticated product. The fact that the output is efficient and requires a certain skill and ability means that this product cannot be easily produced by other countries. Countries that are technologically advanced and have achieved product diversity can be classified into developed countries.

When the findings were examined, it was observed that the cointegration relationship between the variables was not found. Then, according to the results of Dumitrescu-Hurlin panel causality test, which investigated the causality relationship between variables, it was found that there was a one-way panel causality relationship from human development to economic complexity. Based on the conclusions reached within the scope of the study, it can be stated that countries should establish welfare first in order to specialize in production, product diversification and produce sophisticated products. The findings indicate that the implementation of policies aimed at increasing the level of human development for E-7 countries will positively affect the level of economic complexity in these countries. 